\title{
O Género como Instrumento de Definição de Cidades mais Equitativas: Constrangimentos e Oportunidades
}

\author{
Gender as a Way to Define more Equitative and Inclusive Cities: \\ Constraints and Opportunities
}

\author{
Cecília Delgado \\ Universidade Lusíada - Portugal \\ cmndelgado@gmail.com
}

\section{Resumo}

Usou-se como estudo de caso um projeto de requalificação urbanística em Vila Nova de Gaia - Portugal. Questionaram-se homens e mulheres, com diferentes estatutos hierárquicos, sobre o conceito de Qualidade de Vida Urbana, Cidade Ideal e o seu envolvimento na esfera pública. Usaram-se simultaneamente metodologias qualitativas e quantitativas, através do uso de questionários. Os resultados apontam para uma diversidade de perspectivas, não obstante uma imagem 'teórica' de cidade análoga entre géneros. Confirma-se a reduzida presença na esfera pública e lugares de decisão das mulheres. Sabendo que o planeamento urbano não é neutro, importa encontrar os instrumentos para ampliar a voz feminina na esfera de decisão.

Palavras-Chave: Género; Participação Pública; Planeamento Urbano; Qualidade de Vida Urbana.

\begin{abstract}
An urban project in Vila Nova de Gaia Portugal was taken as a case study. Women and men, with different hierarchical status, were asked to define urban life quality, the ideal city model and her/his commitment to the public sphere. It were simultaneously used both qualitative and quantitative methodologies, by means of questionnaires. The results point out to a diversity of perspectives, although there is a consensual "theoretical" city model (quantitative approach), which is analogous in both genders . It was confirmed the little presence of women in the public sphere and in decision-maker positions. Gender mainstreaming has shown that urban planning is not neutral, it's important to find a way to raise women voices among decision-makers.
\end{abstract}

Keywords: Gender; Public Participation; Urban Planning; Urban Life Quality. 


\section{Mainstreaming de género no Urbanismo}

O conceito o mainstreaming de género surgiu pela primeira vez em 1985, na terceira Conferência das Nações Unidas sobre as Mulheres realizada em Nairobi, sendo definido como um meio para atingir a equidade entre géneros, subjacente a todas as atividades, políticas de desenvolvimento, investigação, defesa, legislação, afetação de recursos, planeamento, implementação de programas e projetos ${ }^{1}$. Analogamente, o Conselho da Europa, descreve o mainstreaming de género como: "a abordagem integrada da igualdade de género (...) na (re) organização, na melhoria, no desenvolvimento e na avaliação dos processos de implementação de políticas de igualdade de géneros, a todos os níveis e em todas as fases, pelos atores geralmente implicados na decisão política" ${ }^{2}$.

$\mathrm{Na}$ sequência destas diretrizes, o Tratado de Amesterdão (1997) formaliza um compromisso de mainstreaming de género. Os Estados Membros da Comunidade Europeia assumem a necessidade de desenvolver políticas conducentes com a eliminação de qualquer forma de discriminação contra as mulheres, bem como de adotarem medidas legislativas necessárias à aplicação do princípio da igualdade, com vista a assegurar o desenvolvimento e o progresso das mulheres, nos domínios cultural, político, económico, civil, entre outros.

A União Europeia trabalha na sensibilização para a temática através de diversas diretrizes: Estratégia para a igualdade entre mulheres e homens (20102015); O Roteiro para a Igualdade entre Homens e Mulheres (2006 - 2010); a Estratégia - Quadro da Comunidade para a igualdade entre homens e mulheres (2001 2005).

A promoção da igualdade entre homens e mulheres assume um papel de destaque nas agendas políticas Europeias, com reflexos expectáveis nas políticas internas de cada Estado Membro. Em Portugal, no âmbito da Resolução do Concelho de Ministros 5/2011 de 18 de Janeiro, que estabelece o IV Plano Nacional para a Igualdade, Género, Cidadania e não Discriminação (2011 2013), são definidas várias vertentes de atuação, entre as quais: estratégica $n .^{\circ} 1$ Integração da Dimensão de Género na Administração Pública, Central e Local, como Requisito de Boa Governação; estratégica n. ${ }^{\circ} 5$ - Ambiente e Organização do Território. Enfim, reconhece-se que o ambiente e a organização do território são aspetos particularmente importantes na qualidade de vida das populações, pelo que só uma concepção de espaço e de ambiente que integre a perspetiva de género pode servir de igual modo os homens e mulheres que o habitam.

A legislação Portuguesa de ordenamento territorial é omissa sobre a temática do mainstreaming de género, referindo-se simplesmente a necessidade de prever a igualdade de oportunidades ${ }^{3}$. Segundo Gaspar e Queirós (2008) a perspetiva de género não tem o devido ênfase no planeamento urbano local em Portugal, por ser considerada demasiado detalhada para justificar a sua integração em documentos de política de ordenamento do território, não obstante ser a divisão demográfica mais importante em termos populacionais. Esta condição, causa efeito dos estereótipos de género (ver Ferreira, 2009) $)^{4}$ explica porque o ordenamento do território e a política de ambiente não assume a pertinência do género, com o mesmo ênfase que lhe é concedido nos domínios do emprego e da coesão social (GASPAR e QUEIRÓS, 2008). 


\section{Homens e Mulheres: Diferentes Realidades}

De acordo com o Relatório das Nações Unidas - State of the World Population (2008), mais da metade da população mundial é mulher. Com exceções pontuais entre as quais no Ruanda ou nos países Nórdicos, as mulheres estão praticamente ausentes dos Parlamentos, representado apenas $16,0 \%$ da totalidade dos parlamentares a nível mundial. Por outro lado, as mulheres (incluindo as jovens raparigas) representam $3 / 5$ dos pobres no mundo e, dos 960 milhões de pessoas adultas que não sabem ler $3 / 5$ são mulheres e jovens raparigas 5 . Em curto prazo esta realidade não vai alterar, estima-se que $70,0 \%$ dos 130 milhões de crianças que não tem acesso ao ensino escolar sejam raparigas.

A pobreza e a descriminação salarial ${ }^{6}$ não são o único fator de desigualdade de género. Os estereótipos que arrastam a mulher para um trabalho invisível: cuidar da gestão da casa; filhos e dependentes reduzem a sua disponibilidade para atividades de ascensão pessoal e presença na esfera pública. Desta forma, homens e mulheres usam o tempo e o espaço de forma diferenciada (Healey, 2006), em resultado de opções individuais ou normas culturais.

$\mathrm{O}$ estudo 'The life of women and men in Europe: a statistical portait' (2008) revela que continuam a existir entre homens e mulheres diferenças persistentes em termos de quem cuida dos dependentes (crianças e velhos), disparidades em termos de disponibilidade para o emprego, lazer, etc (Tabela 1). Fatores que se refletem na redução da disponibilidade feminina para participação em áreas como a política e a economia, no acesso aos cargos de decisão, bem como em termos de cuidados individuais.

A Comissão Europeia reconhece que a realização das tarefas quotidianas e domésticas, constitui um obstáculo para a
Tabela 1- Uso do tempo ao longo do dia por género (UE-2008).

\begin{tabular}{|c|c|c|c|c|c|c|}
\hline \multirow[b]{2}{*}{ Minutos / dia } & \multicolumn{2}{|c|}{15 aos 24 anos } & \multicolumn{2}{|c|}{25 aos 44 anos $^{7}$} & \multicolumn{2}{|c|}{ Mais de 65 anos } \\
\hline & $M$ & $\mathrm{H}$ & $M$ & $\mathrm{H}$ & M & $\mathrm{H}$ \\
\hline $\begin{array}{l}\text { Cuidados pessoais } \\
\text { (dormir, comer, outros) }\end{array}$ & 690 & 675 & 654 & 639 & 728 & 734 \\
\hline Emprego & 95 & 133 & 176 & 308 & 6 & 18 \\
\hline Estudo & 146 & 131 & 11 & 11 & - & - \\
\hline Trabalho Doméstico & 113 & 52 & 278 & 116 & 280 & 181 \\
\hline Preparação comida & 23 & 8 & 60 & 17 & 79 & 28 \\
\hline $\begin{array}{l}\text { Lavar, secar, passar a } \\
\text { ferro }\end{array}$ & 9 & 3 & 32 & 16 & 30 & 13 \\
\hline Jardinagem & - & - & 4 & 6 & 12 & 30 \\
\hline Limpeza da casa & 20 & 6 & - & - & 54 & 16 \\
\hline Compras e serviços & - & - & 34 & 20 & 33 & 34 \\
\hline Cuidados c/ as crianças & - & - & 60 & 22 & - & - \\
\hline Trabalho de voluntariado & 6 & 9 & 9 & 10 & 15 & 17 \\
\hline $\begin{array}{l}\text { Trabalhos manuais / } \\
\text { artesanato }\end{array}$ & - & - & - & - & 14 & 0 \\
\hline Lazer & 298 & 345 & 228 & 264 & 362 & 427 \\
\hline $\begin{array}{l}\text { Vida social (família, } \\
\text { amigos, outros) }\end{array}$ & 83 & 83 & 53 & 53 & 54 & 52 \\
\hline Desporto & 28 & 41 & 21 & 26 & 24 & 46 \\
\hline Ver televisão / vídeo & 109 & 120 & 94 & 114 & 160 & 183 \\
\hline Leitura de Livros & 8 & 4 & - & - & 8 & 8 \\
\hline Outro tipo de leituras & 10 & 9 & - & - & 32 & 45 \\
\hline Rádio e música & - & - & - & - & 8 & 10 \\
\hline Entretenimento e cultura & 11 & 10 & - & - & - & - \\
\hline Computadores & 13 & 41 & - & - & - & - \\
\hline Viagens & 88 & 91 & - & - & 44 & 56 \\
\hline Viagem casa/trabalho & 13 & 16 & 21 & 36 & - & - \\
\hline Viagem estudos & 20 & 20 & - & - & - & - \\
\hline $\begin{array}{l}\text { Viagem compras, } \\
\text { crianças }\end{array}$ & 12 & 8 & 28 & 17 & - & - \\
\hline Viagem lazer & 37 & 41 & 25 & 29 & 21 & 26 \\
\hline Viagens domésticas & - & - & - & - & 21 & 25 \\
\hline
\end{tabular}

Fonte: The life of women and men in Europe: A statistical portrait, 2008 (produção da autora - 2012).

incorporação das mulheres no mercado de trabalho em situações de paridade com os homens, admite ainda que a eficácia na realização dessas tarefas depende da estrutura urbana das cidades. A presença das mulheres em cargos de decisão revela igualmente fortes desequilíbrios de género. Tomando como exemplo as instituições Europeias (Tabela 2). Todos os cargos de Presidente são atribuídos a um elemento masculino, cenário que testemunha o afastamento das mulheres dos cargos de decisão. 
Tabela 2 - Homens e mulheres com cargos de decisão nas instituições Europeias (2006).

\begin{tabular}{|c|c|c|c|}
\hline Instituição & Presidente & Mulheres \% & Homens \% \\
\hline Comissão Europeia (comissários) & Homem & 29 & 71 \\
\hline Comissão Europeia (funcionários 1.a) & - & 6 & 94 \\
\hline Membros do parlamento Europeu & Homem & 30 & 70 \\
\hline $\begin{array}{l}\text { Membros do parlamento Europeu } \\
\text { (funcionários } 1 .^{\mathrm{a}} \text { ) }\end{array}$ & - & 18 & 82 \\
\hline Concelho da Europa (funcionários $1 .^{\mathrm{a}}$ ) & - & 17 & 83 \\
\hline $\begin{array}{l}\text { Tribunal de Justiça Europeu } \\
\text { (membros) }\end{array}$ & Homem & 12 & 88 \\
\hline $\begin{array}{l}\text { Tribunal de Auditores Europeus } \\
\text { (membros) }\end{array}$ & Homem & 17 & 83 \\
\hline $\begin{array}{l}\text { Banco Central Europeu (grupo de } \\
\text { decisão) }\end{array}$ & Homem & 6 & 94 \\
\hline Banco de Investimento Europeu & Homem & 4 & 96 \\
\hline Fundo de Investimento Europeu & Homem & 17 & 83 \\
\hline European Social Partners & $\begin{array}{c}96 \% \\
\text { Homens }\end{array}$ & 12 & 88 \\
\hline European ONGs & $\begin{array}{l}70 \% \\
\text { Homens }\end{array}$ & 39 & 61 \\
\hline
\end{tabular}

Fonte: The life of women and men in Europe: A statistical portrait, 2008 ((produção da autora - 2012).

Em Portugal, embora a presença das mulheres no Parlamento tenha vindo a aumentar, está longe da paridade entre géneros (Tabela 3). Também nas Autarquias dados referentes às ultimas eleições (2009) confirmam a reduzida presença de mulheres regista-se uma presença de vinte mulheres entre os trezentos e oito Presidentes de Câmaras ${ }^{8}$ Municipais, ou seja, uma proporção de $6,5 \%$ mulheres para $93,5 \%$ de homens.

Tabela 3 - Homens e mulheres no Parlamento Português (1995-2009).

\begin{tabular}{|c|c|c|c|c|c|}
\hline Legislatura & \multicolumn{2}{|c|}{ Masculino } & \multicolumn{2}{c}{ Feminino } & Total \\
\cline { 2 - 6 } & N. ${ }^{\circ}$ & $\%$ & $\mathrm{~N}^{\circ}$ & $\%$ & $\mathrm{~N} .{ }^{\circ}$ \\
\hline VII (1995) & 309 & 85,36 & 53 & 14,64 & 362 \\
\hline VIII (1999) & 269 & 81,72 & 60 & 18,24 & 329 \\
\hline IX (2002) & 272 & 80,23 & 67 & 19,76 & 339 \\
\hline X (2005) & 265 & 75,28 & 87 & 24,72 & 352 \\
\hline XI (2009) & 340 & 66,53 & 171 & 33,46 & 511 \\
\hline XII (2011) & 315 & 65,76 & 164 & 34,23 & $479^{*}$ \\
\hline
\end{tabular}

Fonte: Assembleia da República. Divisão de Informação Legislativa e Parlamentar (2012); * Dados provisórios (produção da autora - 2012).
Persiste uma enorme pressão para reduzir a discriminação de género na esfera de decisão. Segundo dados estatísticos da União Europeia - UE as mulheres representam $45,0 \%$ dos trabalhadores na União, e apenas 13,7\% dos conselhos de administração das maiores empresas. Observe-se que em Portugal essa percentagem é de apenas $6,0 \%$. Neste sentido a Comissão Europeia quer obrigar as maiores empresas da União Europeia (UE) a ter pelo menos $40,0 \%$ de mulheres entre os membros não executivos dos seus conselhos de administração. A medida proposta pelo executivo comunitário Europeu (2012) propõe que até 2020 todas as empresas cumpram os referidos objetivos.

Neste processo a recente escolarização das mulheres, nos países desenvolvidos, leva a pensar que as desigualdades tenderão a ser reduzidas. É uma ideia falaciosa que contribui para a perpetuação dos desequilíbrios entre géneros: O último relatório da Organização para a Cooperação e Desenvolvimento Económico para a Educação (2012) atesta a melhoria significativa de rendimentos para quem possui uma licenciatura (média de $55,0 \%$ para os países da OCDE) sendo que tal representará um acréscimo de 300.000 euros para um homem e apenas 165.000 euros se for uma mulher. Ou seja, homens e mulheres com o mesmo nível de formação académica não auferem do mesmo poder económico um dos fatores que aliado ao caráter mais introvertido e a menor disponibilidade temporal das mulheres - as impede de estarem presentes na esfera pública. Faz pois sentido que os diferentes níveis de decisão tomem medidas proativas de incentivo à participação e envolvimento feminino.

Entre os vários exemplos possíveis a 'Carta Europeia das Mulheres na Cidade' (1994) reforça o papel das mulheres como cidadãs 
ativas e participativas na vida local, sublinhando o impacto que as questões de género implicam para o desenho da cidade. É referido que as mulheres e os homens vivem a cidade de maneiras diferentes, de acordo com seus papéis e com as suas responsabilidades a partir da divisão sexual do trabalho. Mais recentemente, a 'Carta Europeia para a Igualdade das Mulheres e dos Homens na Vida Local' (2004), promovida pelo Conselho dos Municípios e Regiões da Europa e Parceiros e apoiada pela Comissão Europeia no âmbito do $5^{\circ}$ Programa de Ação Comunitária para a Igualdade das Mulheres e dos Homens, menciona a necessidade do estímulo à participação e uma representação equilibrada das mulheres e dos homens na tomada de decisões e nos cargos de direção como meio de promoção da democracia.

Defende-se que as autoridades locais e regionais são as esferas de governança mais próximas da população, representando os meios de intervenção melhor colocados para combater a persistência e a reprodução das desigualdades promovendo uma sociedade verdadeiramente igualitária. Esta carta, foi publicada em Portugal pela Associação Nacional de Municípios Portugueses, tornando evidente que, pelo menos do ponto de vista teórico, Portugal é sensível a essas questões.

Não obstante a pressão exercida para a incorporação do mainstreaming de género nas diversas vertentes de decisão, nas pratica, a capacidade para introduzir a temática depende da abertura dos próprios governos a essas questões.

$\mathrm{Na}$ Inglaterra o governo criou diretrizes através de legislação própria 'Police Planning Guidance 12' (2000), de modo a que os planos urbanísticos assimilem obrigatoriamente a igualdade, não apenas de género mas também no que se refere aos diferentes grupos etários, etnia e pessoas com necessidades especiais. O Royal Town
Planning Institut desenvolveu o 'Gender Equality and Plan Making: Gender Mainstreaming Toolkit' (GREED, 2003) que pretende guiar as Autoridades Locais na missão de integrar as questões de género nas várias fases de elaboração dos Planos. A forma de atingir o princípio da igualdade passa pela inclusão e monitorização de diversos indicadores e dados estatísticos e a sua subsequente análise e confrontação face às políticas vigentes.

Em Espanha, o Instituto Andaluz de La Mujer editou em 2006 a publicação 'Urbanismo con Perspectiva de Género' (2006) da autora da arquiteta Inês Madariaga. Refere Madariga (2006) que a visão do urbanismo desde o ponto de vista de género pode contribuir para dotar de conteúdo específico o conceito de qualidade de vida que se altera de acordo com os mais diversos fatores, tais como o género, a idade, o status social, etc.

Em Portugal a Comissão para a Cidadania e Igualdade de Género é a entidade responsável pela dinamização desta temática - apoiando o desenvolvimento de estudos, campanhas e politicas de paridade. Até à data foram desenvolvidos pelas Autarquias 10/308 Planos Municipais para a Igualdade de Género, uma das medidas previstas no III Plano Nacional para a Igualdade - Cidadania e Género (2007-2010) com continuidade através do IV Plano Nacional (2011 - 2013).

Trata-se de um instrumento de política global que estabelece uma estratégia de políticas locais que promovam a coesão e o desenvolvimento social ancorado numa visão de desenvolvimento sustentável entre géneros Para além do referido foi estabelecido como mandatório a existência de Planos de Igualdade para todos os organismos estatais. Em síntese, Portugal tem vindo a adotar legislação conducente à redução da discriminação entre géneros, fortemente pressionado pelas politicas igualitárias da 
União Europeia. Não obstante a presença de legislação progressista, no terreno, as alterações carecem de sensibilidade da parte de quem tem o poder para implementá-las.

\section{Hipótese}

No sentido de determinar quais os modelos de cidade mais adequados às necessidades das populações têm sido realizados diversos estudos fundamentalmente no âmbito da temática da Qualidade de Vida Urbana QVU. Em termos metodológicos são usadas predominantemente técnicas quantitativas: uma visão que a análise dos resultados deste estudo tende a demonstrar ser redutora face à triangulação das técnicas metodológicas. Por outro lado, raramente são estabelecidas comparações entre os diversos grupos que compõe a pirâmide de decisão hierárquica: na base - os cidadãos que vivem nas cidades, com poderes limitados de intervenção (homens e mulheres - tendencialmente mais as ultimas); no meio da pirâmide - os técnicos que planeiam as cidades (onde a presença das mulheres é relativamente recente); e no topo os políticos que decidem as politicas urbanas (onde a presença das mulheres é extremamente condicionada). Parte-se do pressuposto de que uma cidade mais equitativa é uma cidade construída a partir da perspetiva de todos e todas.

Admite-se que a reduzida presença feminina na esfera pública e nos lugares de decisão poderá diminuir a probabilidade de ser elencadas e ponderadas as suas necessidades e aspirações - na tomada de decisão - tendo como consequencia a negligência e o aprofundamento das desigualdades entre géneros. A hipótese aqui sustentada é a de que - mulheres e homens não têm as mesmas aspirações e necessidades logo, o 'modelo' de cidade será divergente entre os géneros.

\section{Estudo de Caso - Seleção da Amostra e Metodologia}

A amostra deste estudo é composta por cidadãos, políticos e técnicos ${ }^{9}$, onde a subdivisão de género resulta diretamente da proporção de técnicos e políticos envolvidos no Programa Polis em Vila Nova de Gaia (2000 - 2007). A cidade de Vila Nova de Gaia situa-se na região Norte de Portugal, na margem esquerda do rio Douro, que estabelece a fronteira com a cidade do Porto. É um dos onze municípios que compõem a Área Metropolitana do Porto - AMP ${ }^{10}$.

O Programa Polis consistiu numa intervenção de âmbito territorial protagonizada pelo governo Português e suportada financeiramente pelas Autarquias locais, pela Administração Central e pela Comunidade Europeia. A cidade de Vila Nova de Gaia foi uma das dezoito cidades Portuguesas que em 2000 participaram na iniciativa proposta pelo governo. No caso específico de Vila Nova de Gaia a intervenção estendeu-se por 210 hectares e envolveu a elaboração de quatro Planos de Pormenor ${ }^{11}$ a conceção e construção de vários projetos. Neste âmbito foram melhoradas as acessibilidades através das marginais, requalificados os espaços públicos e áreas verdes, e construídos pequenos equipamentos locais, nomeadamente de apoio à atividade piscatória. A ênfase na participação das populações nas decisões locais foi um elemento inovador do Programa.

Face à hipótese proposta existiam três possibilidades de seleção do universo de estudo: 1) estudar a totalidade da população; 2) estudar uma amostra representativa da população; 3) estudar componentes não necessariamente representativas, mas características da população. Optou-se por estudar grupos, não necessariamente representativos, mas cujas características fossem relevantes para as nossas hipóteses. 
De acordo com Quivi e Campenhoudt (2005) essa é a fórmula mais frequente nas Ciências Sociais. Se o investigador diversificar os perfis dos inquiridos chegará inevitavelmente ao momento de saturação, em que por mais entrevistas que faça dificilmente alcançará informação adicional relevante. Reforça Ghiglione e Matalon (2005) que é raro trabalhar-se com uma amostra perfeitamente representativa.

Em representação dos cidadãos inquiriu-se um grupo de 100 alunos $^{12}$ que frequentava o ano que precede a entrada na universidade. Uma parte significativa dos alunos $(62,0 \%)$ situava-se na faixa etária dos 17 anos. A faixa etária dos 16 e 17 anos representava o grosso da amostra com 50 raparigas $(83,4 \%)$ e 34 rapazes $(85,0 \%)$. No conjunto as raparigas $(60,0 \%)$ predominavam sobre os rapazes $(40,0 \%)$. A taxa de respostas neste grupo totalizou 100,0\% (Tabela 4).

Relativamente ao grupo dos políticos e técnicos inquiriram-se todos os técnicos e políticos envolvidos no Programa. O universo total da população perfez 81 indivíduos (Tabela 4). Destes, 26 foram contabilizados como políticos face à função desempenhada no Programa Polis.

No grupo dos políticos incluíram-se: todos os elementos do Conselho de Administração da GaiaPolis ${ }^{13}$, ou seja, os representantes da $\mathrm{CCDRN}^{14}$, da Autarquia ${ }^{15}$ de Vila Nova de Gaia e da Parque Expo ${ }^{16}$; os Presidentes das quatro Juntas de Freguesia abrangidas pela área de intervenção; o Coordenador Nacional do Programa Polis; o Coordenador da Parque
Expo para o Programa Polis; os dois Diretores Gerais da DGOTDU ${ }^{17}$ e os vereadores da Câmara Municipal de Vila Nova de Gaia. Admite-se que estas categorias possam não ser rigorosamente estanques e exclusivas.

O grupo dos 55 técnicos englobou as equipas dos quatro Planos de Pormenor, os arquitetos autores dos projetos elaborados no âmbito do Programa Polis e os contratados pela GaiaPolis, os funcionários da CCDRN e da Câmara Municipal de Vila Nova de Gaia, a equipa da GaiaPolis que geriu o Programa Polis e os arquitetos responsáveis pelos projetos desenvolvidos nos principias lotes privados.

A faixa etária destes dos técnicos e políticos variou entre os 28 e os 68 anos de idade. No que respeita à representação por sexos destaque para a ausência de mulheres no grupo de políticos $(\mathrm{p}=0,001)$, o que confirma a ausência das mulheres na esfera de decisão. No total o sexo feminino representava $37,5 \%$ da amostra sendo a faixa etária média inferior a dos homens $(p=0,008)$. Registe-se, ainda, a predominância da faixa etária mais jovem no grupo dos técnicos face a presença das mulheres $(\mathrm{p}=0,033)$.

A formação académica entre políticos e técnicos era igual ou superior à licenciatura, no entanto registaram-se três casos de formação inferior à licenciatura no grupo dos políticos A área académica predominante nos técnicos era a da arquitetura $(79,2 \%)$ e nos políticos a engenharia (42,8\%). A maioria dos técnicos e políticos residia no Porto $(41,2 \%)$,

Tabela 4 - Composição da amostra por género e grupos de decisão.

\begin{tabular}{|c|c|c|c|c|c|}
\hline & $\begin{array}{c}\text { H+M-Pop- } \\
\text { Total Po }\end{array}$ & $\mathrm{H}+\mathrm{M}-\operatorname{Resp}$ & $\begin{array}{l}\% \text { relativa } \\
\text { Pop Total }\end{array}$ & $\begin{array}{c}\text { N. }{ }^{\circ} \text { Homens - } \\
\text { Resp }\end{array}$ & $\begin{array}{c}\text { N. }{ }^{\circ} \text { Mulheres- } \\
\text { Resp }\end{array}$ \\
\hline Políticos & 26 & 21 & 80 & 21 & 0 \\
\hline Técnicos & 55 & 47 & 85 & 29 & 18 \\
\hline Cidadāos & $100^{*}$ & 100 & 100 & 40 & 60 \\
\hline
\end{tabular}

* O grupo de politico e técnicos representa a população total. Os cidadãos uma amostra 
em segundo lugar em Vila Nova de Gaia (29,4\%), em Lisboa residiam $(17,7 \%)$ dos inquiridos, e noutras cidades $(14,7 \%)$. No conjunto $82,3 \%$ residiam na área Metropolitana do Porto - AMP e 17,7\% fora da AMP.

A taxa de respostas dos homens foi de $79,4 \%$ e nas mulheres de $100,0 \%$. Regista-se uma relação estatística entre ser-se homem e a possibilidade de ocupar lugares de decisão política $(\mathrm{p}=0,001)$ e entre ser-se mulher e viver mais próximo da área de trabalho $(\mathrm{p}=0,022)$.

$\mathrm{Na}$ formulação do inquérito e da entrevista consideraram-se as observações resultantes do pré-teste realizado no contexto de vizinhança. Nessa fase tinham sido detetados alguns problemas de linguagem que não podendo ser atribuídos a falta de escolaridade dos inquiridos, estariam eventualmente relacionadas com a formação académica, o contexto sócio - profissional ou o nível etário da amostra.

Face ao exposto optou-se por utilizar diferentes abordagens linguísticas, de onde as diferentes formatações: inquérito aos cidadãos; entrevista aos técnicos e políticos. A entrevista realizada ao grupo dos técnicos e políticos teve como antecedente a realização de um segundo pré-teste cuja minuta inicial resultou demasiada extensa e de conteúdo generalista. Neste sentido, preferiu-se uma entrevista constituída por uma proporção idêntica de perguntas abertas e semifechadas. A construção das entrevistas e dos inquéritos foi baseada na pesquisa teórica, em especial sobre a temática da qualidade de vida urbana. Nas entrevistas aos técnicos e políticos foi ainda possível incorporar os resultados preliminares obtidos no inquérito aos cidadãos.

Nos dois questionários foram usadas perguntas filtro, tendo como referência a dialética entre a cidade generalista e o caso estudo. No inquérito fornecido aos cidadãos foi usado como filtro a cidade de Vila Nova de Gaia, nas entrevistas administradas aos políticos e técnicos, o Programa Polis em Vila Nova de Gaia.

A amostra foi recolhida em dois períodos, o primeiro abrangeu a realização dos inquéritos aos 100 alunos, nos meses de Outubro a Novembro de 2007. Num segundo tempo decorreu a realização das entrevistas aos políticos e técnicos, com início em Novembro de 2007 e conclusão em Junho de 2008.

Aplicaram-se dois tipos de abordagens metodológicas: através da técnica quantitativa inquiriram-se os políticos e técnicos sobre o 'modelo' de qualidade de vida urbana - QVU; numa segunda fase, usou-se a técnica qualitativa para descrever a Cidade Ideal.

Foram ainda realizados testes estatísticos: na análise dos resultados sobre a definição da qualidade de vida urbana aplicaram-se os teste de Kruskall - Walis e de Mann Whitney; na Cidade Ideal, face a dimensão da amostra e a saturação das respostas, foi possível aplicar o teste de Qui - Quadrado. Considerou-se estar perante uma correlação estatisticamente significativa sempre que $\mathrm{p} \leq$ 0,050 .

\section{Resultados - Qualidade de Vida Urbana e Cidade Ideal}

Para aferir o modelo de qualidade de vida urbana (analise quantitativa), usou-se uma listagem de vinte e sete parâmetros ${ }^{18}$. Inquiriram-se mulheres e homens (grupo dos técnicos e políticos) sobre a importância relativa de cada parâmetro. Segundo esse 'modelo' os parâmetros mais relevantes para ambos os géneros são os transportes públicos, as infraestruturas, os espaços verde e qualidade ambiental. Em sentido inverso, foi considerada menos relevante, a presença da indústria, a proximidade casa - trabalho e a 
sociabilização.

Da comparação homens vs mulheres não registou nenhuma variação estatisticamente significativa. Como pergunta filtro optou-se por avaliar a Qualidade de Vida Urbana na área de intervenção do Programa Polis em Vila Nova de Gaia usando-se a mesma listagem de parâmetros. A comparação entre géneros permite verificar uma perceção ligeiramente mais positiva por parte das mulheres relativamente a qualidade de vida urbana na área de Intervenção Polis.

No entanto, existe um conjunto de parâmetros que diferenciam os géneros. Por exemplo, as mulheres percecionam como tendo menos QVU do que os homens, parâmetros como: a mobilidade; os estacionamentos; os transportes públicos; a indústria; a qualidade ambiental; a recolha de resíduos; a segurança urbana; a envolvente paisagística; a identidade territorial e os serviços. No conjunto existem dez parâmetros avaliados pelas mulheres abaixo da apreciação masculina, ou seja ligeiramente mais do que $1 / 3$ do total dos parâmetros listados. Neste grupo de parâmetros, deve ser destacado que três deles estão relacionados com meios de transporte: mobilidade; estacionamentos; e transportes públicos. O que, de acordo com Gaspar e Queirós (2008), reflete uma debilidade sentida especialmente pelo sexo feminino.

Homens e mulheres não percecionam do mesmo modo as distâncias entre a habitação e o comércio $(p=0,045)$, a habitação e os serviços e equipamentos de apoio $(\mathrm{p}=0,008)$. Verifica-se ainda uma tendência não estatisticamente significativa $(p=0,059)$ por parte dos homens para avaliar negativamente o parâmetro 'proximidade casa - trabalho'.

Em sentido inverso, são as mulheres quem perceciona menor qualidade na avaliação do parâmetro 'recolha de resíduos sólido' $(p=0,013)$. Por fim, registe-se a tendência não estatisticamente significativa das mulheres para classificar negativamente a indústria na área de intervenção do Programa Polis em Vila Nova de Gaia ( $p=0,058)$.

Ao questionar a nossa amostra de técnicos e políticos sobre a Qualidade de Vida Urbana - QVU na área de intervenção Polis, foi considerada a possibilidade de desconhecimento dos mesmos. Os resultados demonstram que há parâmetros considerados muito importantes para a QVU e cujo nível de desconhecimento é bastante elevado: no grupo dos homens, mencionem-se os transportes públicos $(44,0 \%)$ e os equipamentos escolares $(40,0 \%)$; para as mulheres os transportes públicos $(38,9 \%)$.

No entanto o desconhecimento é assumido com maior veemência pelas mulheres. Atente-se aos três parâmetros com maior diferencial entre géneros: equipamentos de apoio a terceira idade $(\mathrm{H}-54,0 \%$; $\mathrm{M}-$ $83,3 \%)$; participação pública ( $\mathrm{H}-30,0 \% ; \mathrm{M}-$ $55,6 \%)$; indústria $(\mathrm{H}-44,0 \% ; \mathrm{M}-66,7 \%)$.

Os cinco parâmetros onde as mulheres apresentam maior desconhecimento são: os equipamentos de apoio a terceira idade $(83,3 \%)$; a indústria $(66,7 \%)$; a participação pública $(55,6 \%)$; os equipamentos escolares $(50,0 \%)$ e a proximidade casa - trabalho $(44,4 \%)$. Para os homens o maior desconhecimento corresponde: aos equipamentos de apoio a terceira idade $(54,0 \%)$; aos transportes públicos $(44,0 \%)$; a indústria $(44,0 \%)$ aos equipamentos escolares $(40,0 \%)$; aos equipamentos de saúde $(38,1 \%)$. Note-se, aqui, a maior predisposição feminina para afirmar desconhecimento embora todas $(100,0 \%)$ da mulheres residam na proximidade (ou seja dentro da AMP) e apenas 76,0\% dos homens estejam nas mesmas condições.

$\mathrm{Na}$ comparação por géneros existe apenas um parâmetro com diferença estatística significativa, que corresponde a perceção da qualidade dos equipamentos para a terceira idade $(p=0,028)$. Verifica-se que são os 
homens $(46,0 \%)$ quem mais afirmam ter conhecimentos suficientes para avaliar a qualidade destes equipamentos. Nas mulheres essa percentagem é reduzida para 16,7\%. Relativamente a avaliação do conhecimento sobre a qualidade da participação pública no âmbito da intervenção do Polis, o resultado obtido não é estatisticamente significativo $(\mathrm{p}=0,054)$. Não obstante é de registar a tendência para serem os indivíduos masculinos quem, em maior número, afirma ter conhecimentos suficientes para avaliar a qualidade da participação pública $(70,0 \%)$, comparativamente as inquiridas mulheres $(44,4 \%)$.

\section{Cidade Ideal}

\section{Mulheres e Homens - Técnico e Políticos}

Numa segunda fase do estudo solicitou-se a descrição livre da cidade ideal (análise qualitativa). As mulheres (grupo dos técnicos) associaram o comércio ideal ao comércio de rua $(\mathrm{p}=0,029)$ e não ponderaram a coexistência deste com as grandes superfícies comerciais, condição admitida pelos homens $(\mathrm{p}=0,028)$.

Relativamente a indústria verifica-se que existe uma ponderação por géneros diferenciada. As mulheres são quem mais rejeita a possibilidade de integração da indústria na cidade, mesmo que com funções compatíveis $(p=0,014)$. Sublinhe-se ainda a tendência não estatisticamente significativa para o sexo feminino, em associar o lazer ao uso dos espaços verdes $(p=0,057)$.

\section{Mulheres e Homens - Cidadãos}

A comparação dos atributos da cidade ideal descrita pelos homens e mulheres (grupo dos cidadãos) corrobora da importância dos espaços verdes no cenário idílico do espaço habitacional $(p=0,042)$. É também significativa a rejeição do sexo feminino em relação à ausência desta característica no espaço habitacional $(p=0,047)$, o que reforça a relação anterior. Do mesmo modo verifica-se que a associação do lazer aos espaços verdes é fundamentalmente feminina $(p=0,017)$. No comércio observa-se a rejeição do sexo feminino em relação a espaços descritos como: 'pequeno, abafado, fechado' $(\mathrm{p}=0,011)$. Estas características são evitadas pelas mulheres, igualmente no local de trabalho $(\mathrm{p}=0,030)$.

A preferência pela habitação unifamiliar não se distribui uniformemente entre os géneros sendo uma opção essencialmente feminina $(p=0,024)$. São também as mulheres quem rejeita os espaços com barulho, agitados, poluídos e sujos $(\mathrm{p}=0,001)$ preferindo os espaços mais calmos.

\section{Discussão sobre o 'modelo' de QVU e de Cidade Ideal}

Políticos (sem a presença de mulheres) e técnicos (onde os dois géneros estão presentes) admitem dois cenários possíveis e diferenciados: um 'modelo' baseado no conceito de Qualidade de Vida Urbana $\left(1^{\circ}\right)$ e outro na Cidade Ideal $\left(2^{\circ}\right)$.

No primeiro, sublinhe-se a neutralidade do género e da 'posição hierárquica de decisão', ou seja, os homens e as mulheres que desempenham funções de técnicos e / ou políticos partilham uma visão de cidade comum. Atente-se que esta neutralidade aprece com indiferente às variações nas rotinas do dia a dia dos homens e mulheres (e faixas etárias), descritas no relatório The life of women and men in Europe (2008). Este 'modelo' também não corresponde à descrição de um lugar habitacional com QVU - como descrita pelos homens e mulheres cidadãos. Admite-se como provável que essa neutralidade resulte da estandardização dos 
modelos urbanos, em consequência da formatação académica como Hershberger (2008) e Madariaga (2006) haviam sublinhado.

Outra relevante conclusão decorre da comparação da importância do parâmetro e do seu conhecimento. Os resultados demonstram que a importância atribuída, não é correlativa ao grau de conhecimento in loco desse mesmo parâmetro. Uma situação evidente, por exemplo, nos transportes públicos. Este aspeto é particularmente notório nos políticos e nos homens, dois grupos que se interpenetram, pelo que não será incorreto afirmar que reflete um maior domínio na 'arte de argumentar'. Neste sentido, importa também refletir sobre o modo como se legitimam discursos não fundamentados em conhecimento real.

Assinale-se que as mulheres - cujo facto de residirem na proximidade apontaria para um maior conhecimento - afirmam maior desconhecimento em parâmetros como os equipamentos de apoio à terceira idade, uma vertente dos cuidados que é tradicionalmente feminina. Dos resultados referidos sobressaem diferentes atitudes de género homens mais dispostos e expressar uma opinião/avaliação sobre os paramentos, independentemente da profundidade do seu conhecimento da situação real - mulheres com maior retraimento.

Por fim, os géneros não percecionam a cidade da mesma forma, avaliando a sua qualidade de forma diferenciada. Por exemplo, as mulheres avaliam mais favoravelmente: a distância casa - trabalho (o que pode ser explicado pelo facto de residirem na AMP); a distância entre a casa e os equipamentos/serviços de apoio; a avaliação da atuação do Polis; e do seu contributo para a imagem externa e interna da cidade sendo, por norma, menos criticas e auto afirmativas, fatores que numa sociedade competitiva e homocêntrica não contribuíram, à priori, para imergirem na esfera pública.

No que respeita a Cidade Ideal evidenciase uma clara divergência relativamente ao modelo de QVU anteriormente descrito. A Cidade Ideal dos políticos e técnicos (homens e mulheres) sustenta-se na diversidade funcional, na proximidade, na cidade policêntrica, algo a que Archer (2007) considera como sendo parte dos novos princípios do Urbanismo moderno e que sustenta um retorno à cidade tradicional. Note-se, no entanto a exceção da indústria, que de acordo com a nossa amostra feminina, deverá ser preferencialmente implantada fora dos núcleos urbanos. Homens e mulheres defendem ainda diferentes conceitos para o comércio - as mulheres mais suportado no comércio de rua e apenas estas tendem a associar o uso do espaço verde à prática de lazer.

\section{Cidade ideal dos cidadãos}

A cidade ideal dos cidadãos, determinada pelo 'senso comum' e pela praxis quotidiana não diverge substancialmente da visão da cidade ideal dos técnicos e políticos. Tem espaços verdes, é calma e sossegada e com habitação unifamiliar ${ }^{19}$. Existe a mistura funcional, com o comércio de proximidade apoiado nas grandes superfícies comerciais. Esta descrição coincide com a caracterização de uma área residencial com boa qualidade de vida urbana, de acordo com a representação deste grupo.

Da comparação por géneros sublinha-se a importância atribuída aos espaços verdes pelo sexo feminino, simultaneamente nas zonas habitacionais e de lazer, a rejeição dos espaços pequenos e fechados, nos espaços comerciais e de trabalho.

Numa segunda fase trabalhou-se a representação da cidade ideal deste grupo através de exemplos concretos em Vila Nova de Gaia. Aqui, a valorização da calma e 
sossego assume a primazia, em detrimento dos espaços verdes e da habitação unifamiliar. Em quarto lugar surge a proximidade ao comércio / serviços e equipamentos de apoio. $\mathrm{O}$ comércio focaliza-se quase exclusivamente nas áreas comerciais concentradas. No lazer, valorizam-se os espaços verdes e a praia. No trabalho as acessibilidades e os transportes públicos.

A influência do género demonstra ser determinante na preferência pela habitação unifamiliar e na rejeição do barulho, agitação e poluição, no lazer. Por outro lado, o facto de se habitar numa habitação unifamiliar, determina a valorização da calma e sossego.

Em síntese, os resultados atestam que numa perspetia teórica de construção do modelo de Qualidade de Vida Urbana, homens e mulheres, sejam técnicos ou políticos convergem na defesa de uma cidade que reflete um modelo funcionalista - divisão funcional, valorização dos transportes públicos, acessibilidades e mobilidades em detrimento à proximidade funcional $\mathrm{e}$ sociabilização - fatores caracterizadores da cidade tradicional.

Já no plano emocional e afetivo defendem outro modelo - sustentado na cidade tradicional - em especial as mulheres que sublinham a importância da proximidade e do comercio de rua. Para mais este "modelo" que resulta da descrição da 'Cidade Ideal' - a que chamaremos de 'afetivo' - aproxima-se da narração da cidade ideal e com Qualidade de Vida Urbana que nos é descrita pelos cidadãos.

Qual dos modelos empregam os técnicos na sua prática profissional e quais as consequências que daí advém? Não se pode, como rigor, responder a estas duas questões que se afastam dos objetivos do presente trabalho. No entanto, sabendo que o vetor humanístico é o mais débil na formação dos arquitetos (Brandão, 2005) e, dada a forte implantação do conceito de planeamento à
Barcelona $^{20}$ ou funcionalista, que fundamenta o modelo 'teórico'21, é admissível a preponderância do primeiro no desenho das politicas urbanas.

Independentemente do 'modelo' adotado, conclui-se que o género, em paralelo com outros fatores não apresentados neste artigo (como a faixa etária, a formação académica, a formação profissional, o grupo sócio económico, a área de residência, entre outros) se assumem como elementos diferenciadores na perceção da realidade e das necessidades e aspirações de cada um e de cada uma.

\section{Resultados - Participação Pública}

\section{0 acesso a esfera pública}

A participação é correlativa a ideia de igualização, um fator fortemente influenciado pelos estereótipos nacionais, pelos valores culturais, mas também pela importância que a agenda política lhe atribui (Ferreira, 2009). No terreno os lugares de decisão são, em geral, considerados como uma responsabilidade masculina. As ambiguidades e contradições no desenvolvimento, implementação e prática das políticas de igualdade persistem, como confirmam os resultados: as mulheres não ascendem aos lugares políticos $(p=0,001)$. Temos também uma diferenciação na distinção entre o género e a atividade profissional. Para os homens a sua participação em fóruns públicos mesmo quando não estando em representação profissional não pode ser dissociada das funções profissionais, ou seja - pessoa (tendencialmente homem) $=$ profissional $(\mathrm{p}=0,033)$ (Tabela 5).

Reforçando o resultado anterior as poucas mulheres (técnicas) que afirmam 'ter participado' basearam-se no uso do 'poder de decisão', uma lógica fortemente alicerçada no perfil masculino de atuação, de onde resulta uma redução significativa da participação feminina $(\mathrm{p}=0,001)($ Tabela 6$)$. 
Tabela 5 - Homem vs mulher - Influência do género na probabilidade de participação como cidadão anónimo.

\begin{tabular}{ccc}
\hline $\begin{array}{c}\text { Não distinguir } \\
\text { entre anónimo / } \\
\text { técnico / político }\end{array}$ & Masculino $(\mathrm{N}=25)$ & Feminino $(\mathrm{N}=11)$ \\
Sim & 8 & 0 \\
Não & 17 & 11 \\
\hline
\end{tabular}

${ }^{2}\left({ }_{2}\right)=3,82 ; p=0,033$

Ainda sobre a discussão em torno da participação nos fóruns de discussão pública, das mulheres e homens, atente-se conjuntamente ao discurso moderado do sexo feminino. Todos os elementos deste grupo de técnicos e políticos residiam na Área Metropolitana do Porto, logo seria expectável um maior conhecimento da realidade em análise. No entanto, os resultados demonstram serem as mulheres quem admite níveis de desconhecimento maior em relação aos parâmetros avaliados para o estudo de caso. Sendo menos afirmativas (independentemente da maior legitimada das suas opiniões) a probabilidade deste grupo se fazer ouvir na esfera de decisão será menos elevado.

\section{Discussão}

Os resultados comprovaram que a função exercida profissionalmente é relevante para o acesso à esfera pública e simultaneamente o ser mulher. Decorrente dos resultados, a esfera pública é seletiva, i.e. não é representativa da vontade de todos e todas. Neste sentido, as cidades não são o lugar da inclusão, da diversidade, do respeito pela diferença, do processo de construção do bem social baseado na ética, mas espaços condicionados pelo padrão das minorias que tem assento na esfera de decisão.

Neste cenário, as representações dos diferentes atores, políticos, técnicos e cidadãos, não é relevante, face a diferente
Tabela 6 - Homens vs mulheres - Influência do género na probabilidade de participação como técnico ou politico.

\begin{tabular}{ccc}
\hline $\begin{array}{c}\text { Participação como } \\
\text { Técnico/ Político }\end{array}$ & Masculino $(\mathrm{N}=50)$ & Feminino $(\mathrm{N}=18)$ \\
Sim & 42 & 8 \\
Não & 8 & 10 \\
\hline${ }^{2}\left({ }_{2}\right)=10,64 ; \mathrm{p}=0,001$ &
\end{tabular}

acessibilidade, a esfera publica entre géneros. Neste sentido, embora políticos, técnicos e cidadãos, convirjam em relação a ideia de que a participação pública sendo importante, não se fomenta, o verdadeiro enfoque coloca-se primordialmente no género que exclui mulheres, jovens e populações menos qualificadas academicamente do espaço de debate $^{22}$. Fomenta-se assim o imperialismo da visão homogenizante e homocêntrica, assente num sistema de dominação.

\section{Conclusões}

A necessidade de capacitar todos os atores envolvidos no processo de construção de cidades mais equitativas e inclusivas, incluindo os decisores, tem sido veiculada em diversos instrumentos políticos, nomeadamente, o Tratado de Amesterdão (1997) ou a Carta de Leipzig (2007). A pertinência da participação de todos e todas, mas muito especialmente dos grupos menos representados na esfera pública, como as mulheres é o tema de vários documentos estratégicos, como a: Carta Europeia das Mulheres na Cidade (1994); ou a Carta Europeia para a Igualdade das Mulheres e dos Homens na Vida Local (2004).

A cidade não pode ser o resultado de um pensamento único, i.e. a ideologia dominante. Deve ser um espaço democrático onde o coletivo e o individual devem ser simultaneamente respeitados. $\mathrm{O}$ debate contemporâneo mostra-se sensível a essa 
nova realidade tendo sido produzidos diversos documentos que comprovam a pertinência e preocupação dos pares relativamente a esta temática: a 'Nova Carta de Atenas' (2003), a qual propõe uma nova visão humanizada, em que as pessoas são o foco da decisão. As diretrizes propostas no relatório 'New vision for planning' do Royal Planning Institut (2001), o Projeto ReUrBa2 (2007) ou ainda os 'Novos Princípios do Urbanismo' da autoria de François Archer (2007), difundem as preocupações mundiais da sociedade civil e académica nessa direção. Tratam-se de documentos 'manifesto' de abrangência fundamentalmente Europeia, embora esta seja uma preocupação presente à escala planetária como testemunha a 'Carta Mundial do Direito à Cidade'.

Sendo o indivíduo, na conceção holística do termo, o foco do pensamento urbanístico contemporâneo, o cânone, homem, branco, instruído e de meia idade, não pode ser o 'modelo' padrão. É preciso salvaguardar as necessidades e aspirações dos outros: mulheres, velhos, jovens, crianças, iletrados, minorias étnicas, i.e., a diversidade que caracteriza as cidades.

As mulheres estão em paridade estatística na população. A sua ausência da esfera pública decorre de condicionantes culturais amplamente reconhecidas. O ênfase que se assume relativamente a este grupo, pretende apenas repor um padrão de justiça e ética na vivencia das nossas cidades.

Hoje, o mainstreaming de género é uma referência incontornável no planeamento urbano, embora com reduzida repercussão em Portugal. Por outro lado, o Direito à Cidade, fundamento da justiça espacial e social, para todos e todas, é uma questão contextualizada como metafísica, logo pouco adotada num país de brandos costumes e patriarcal, onde se escamoteiam as desigualdades sociais, 0 racismo e a pobreza. Este 'virar de costas' é também efeito da vacuidade do debate e da produção científica, especialmente no campo disciplinar do planeamento urbano, da falta de uma cultura de partilha de ideias e de discussão cruzada no meio académico. Como afirmava Brandão (2005-a) em Portugal vivese o culto do status, de onde as preocupações sociais serem irrelevantes. Preferem-se os valores da sociedade capitalista, que catapultou Portugal para a crise financeira atual. Uma crise que é também, no nosso entender, uma crise de valores humanos.

Pelo exposto, promover o espaço para a cidadania ativa assume-se como o caminho óbvio, mas este processo envolve uma premissa preliminar: os cidadãos estarem informados. Um indivíduo sem informação está "impedido" de ter opinião. Retomado a Portugal existem os instrumentos legislativos que concedem o direito a informação e participação dos cidadãos, nomeadamente a Constituição da República Portuguesa e o Código de Processamento Administrativo. Assim sendo, a reduzida atividade participativa decorre do desconhecimento dos direitos e deveres dos cidadãos, de onde ser importante a capacitação de todos os agentes envolvidos: de cima para baixo e de baixo para cima.

O caso - estudo comprova que os cidadãos não estão, nem são informados, incluindo os seus representantes legítimos. Demonstra também que os técnicos e políticos desconhecem o conceito e a pertinência da participação das populações, condição que dificulta o bom funcionamento da democracia.

Em síntese:

1. As mulheres e homens tem opiniões, aspirações e necessidades diferentes, no entanto, pratica-se um urbanismo neutro que se afirma como uma falsa visão coletiva;

2. As mulheres estão ausentes da esfera de decisão;

3. A ausência de diálogo impede que as 
cidades reproduzam as necessidades e aspirações de todos e todas;

Sustentamos ser a visão de género fundamental para a construção de cidades mais equitativas e inclusivas, uma vez que o género influencia a forma de vivenciar e da apropriação do espaço. Em resultado de opções individuais ou condicionantes de culturais as necessidades e aspirações dos homens e das mulheres são diversas. A ausência das mulheres da esfera pública e do topo da hierarquia de decisão condiciona a inclusão das diferentes perspetivas no desenho da cidade.

Não obstante importa salvaguardar a questão de classe social. As necessidades e rotinas da mulher de classe alta não são necessariamente as mesmas da classe baixa. As mulheres que chegam a postos de decisão possuem um estatuto económico que lhes permitem ajudas diferenciadas relativamente a mulher sem recursos económicos. Por outro lado, as mulheres que rompem 'o telhado de vidro' sofrem um processo de aculturação homogeneizante. (Madariaga, 2006).

Em suma, existe ainda um longo processo reflexivo para fazer em torno destas questões. Muito mais do que leis inovadoras e igualitárias, setor onde muito tem sido feito, é preciso ir para o terreno e conhecer a realidade. A mudança tem que ser construída pelo coletivo. A capacitação de todos e todas, assume-se como a condição para o diálogo. Dar a voz aos cidadãos implica mais do que um direito teórico, implica criar o espaço físico onde a democracia deliberativa seja um processo dinâmico de diálogo contínuo, com ou sem consenso, mas obrigatoriamente através do respeito da diversidade subjacente ao direito de todos e todas à cidade equitativa e justa. Reconhecer os constrangimentos existentes é uma oportunidade para a mudança.

$\overline{1}$ De acordo com a definição

estabelecida pela OSAGI - Office of the special adviser in gender issues and advancement of women department economic and social affairs. Em http://www.un.org/womenwatch/osagi/gender mainstreaming.htm

2 Relatório Final de Actividades do Grupo de Especialistas para uma Abordagem Integrada da Igualdade (1999) Lisboa: Edição Conselho da Europa, CIDM, Gabinete da Ministra para a Igualdade, Presidência do Conselho de Ministros. p. 14.

3 Ver o Art. $^{\circ} 3^{\circ}$, da Lei n. ${ }^{\circ} 48 / 98$, de 11 de Agosto (Lei de Bases do Ordenamento e Território Urbano - LBOTU; Decreto Lei n. ${ }^{\circ}$ 380/99, de 22 de Setembro (Regime Jurídico dos Instrumentos de Gestão Territorial RJIGT); Programa Nacional das Políticas de Ordenamento do Território - PNPOT (2007); Quadro de Referência Estratégico Nacional QREN 2007-13; entre outros.

4 Segundo Ferreira (2009), os estereótipos de género vigentes em Portugal são oshomens com preferência nos empregos, a união da família mais importante que a vida afectiva do casal e as mulheres deverem reduzir as horas de trabalho remunerado em prol da família.

5 Dois factores determinantes para $\mathrm{o}$ afastamento da esfera pública deste grupo. Ver, Freire (2009 [1968]) em 'Pedagogia do Oprimido'.

6 As mulheres recebem em média menos $16,40 \%$ do ordenado dos homens em funções similares (Annual Report to the European Institutions - European Union Agency for Fundamental Rights - FRA, 2011).

7 Não existem dados disponíveis para a faixa etária entre os 45 e os 64 anos de idade. 
Brasil.

$8 \quad \mathrm{O}$ correspondente à prefeitura no

$9 \quad$ No que concerne ao grupo de políticos e técnicos foi estudada a população total e não apenas uma amostra. Relativamente aos cidadãos é tecnicamente correto afirmar de que se trata apenas de uma amostra.

10 A Área Metropolitana do Porto (AMP) abrange uma população total de 1.394.046 habitantes. Fonte: INE 2008.

11 Documento escrito e desenhado de natureza administrativa que define a ocupação, o uso e transformação do solo na área abrangida pelo referido instrumento de ordenamento territorial.

12 A população total dos alunos que frequentavam o último ano do ensino secundário, na Escola Inês de Castro situada na zona de intervenção do Programa Polis. Estamos perante uma amostra não representativa, mas com características relevantes para a nossa hipótese. Entende-se que os jovens estão num período formativo particularmente sensível onde a apropriação do espaço é mais intensa. Uma parte destes jovens entra na vida ativa imediatamente após a conclusão do secundário, outros entrarão nos três anos seguintes, concluído o curso universitário. Sublinhe-se ainda que a Constituição da República Portuguesa estabelece o direito de voto a partir dos 18 anos de idade, no entanto esta faixa etária é sintomaticamente afastada e/ou a sua voz negligenciada no debate público.

13 GaiaPolis - Empresa local responsável pela gestão do Programa Polis em Vila Nova de Gaia.

14 CCDRN - Comissão de Coordenação e Desenvolvimento Regional do Norte -
Portugal.

$15 \mathrm{O}$ correspondente à prefeitura no Brasil.

16 Parque Expo - Empresa semipública a quem o governo atribuiu a elaboração dos 18 Planos Estratégicos no âmbito da primeira fase do Programa Polis. A empresa ficou responsável pela gestão local de 10 cidades, entre as quais de Vila Nova de Gaia.

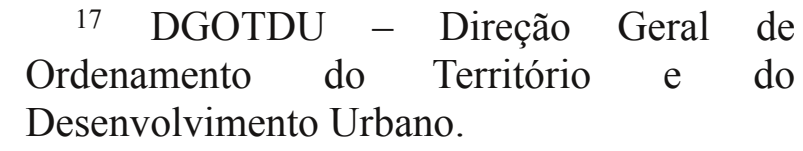

18 Listagem total dos parâmetros: Equipamentos apoio a Terceira - Idade; Indústria; Transportes Públicos; Equipamentos Escolares; Equipamentos Saúde; Proximidade Casa - Trabalho; Participação pública; Serviços de apoio ao cidadão; Equipamentos Desportivos; Recolha de Resíduos; Proximidade Habitação Equipamento e Serviços de apoio; Segurança Urbana; Sociabilização; Equipamentos Culturais e de Lazer; Habitação; Comércio; Identidade Territorial; Proximidade habitação - Comércio; Infraestruturas; Planeamento Urbano; Estacionamentos; Património; Qualidade Ambiental; Mobilidade; Espaços Verdes; Acessibilidades; Envolvente Paisagística; Outros.

19 A idealização pela casa individual é também partilhada pelos Franceses. Ver, Ascher, F. (2010). Novos Princípios do Urbanismo seguido de Novos Compromissos Urbanos, um léxico. (L. Horizonte, Ed.) Lisboa, Portugal: Livros Horizonte.

20 Designação introduzida por Maricato, Erminia (2008). Brasil, cidades alternativas para a crise urbana. Petropolis, Rio: Vozes.

21 Definido através da conceptualização do modelo de Qualidade de Vida Urbana - 
descrito pelos politico e técnicos.

22 Resultados não apresentados neste artigo.

\section{Referências}

ASCHER, François. Los Nuevos Principios del Urbanismo: El fin de las cidades no está a la ordem del dia. Madrid: Alianza Editorial. 2007.

BRANDÃO, Pedro. Ética e Profissões, no Design Urbano. Convicção, responsabilidade $\mathrm{e}$ interdisciplinaridade. Traços da Identidade Profissional no Desenho da Cidade (Tese de Doutoramento não publicada). Barcelona: Universidade de Barcelona. 2005.

BRETON, Philippe. A palavra manipulada. Lisboa: Editorial Caminho. 2001.

Conselho Europeu de Urbanistas. Nova Carta de Atenas. 2003.

FERREIRA, Pedro. Juventude e género no espaço público europeu. In: BRABO, Tânia (org.) Gênero, educação e política: múltiplos olhares. S. Paulo: Ícone e FAPESP, 2009, p. $49-58$.

FREIRE, Paulo. Pedagogia do Oprimido.

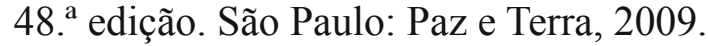

GASPAR, Jorge; QUEIRÓS, Margarida. Género, Território e Ambiente: Estudo de diagnóstico, criação de indicadores de género na área do ambiente e território e guia para o mainstreaming de género. Comissão para a Igualdade do Género (CIG), Lisboa, 2008.

GHIGLIONE, Rodolphe; MATALON, Benjamin. $\mathrm{O}$ inquérito, Teoria e Prática. Oeiras: Celta Editora, 2005.
GREED, Clara. Gender Equality and Plan Making: Gender Mainstreaming Toolkit, London: Royal Town Planning Institute, 2003.

HEALEY, Patsy. Collaborative Planning: Shaping places in Fragmented Societies. 2. Edição. U.S.A: Palgrave Macmillan, 2006.

HERSHBERGER, Robert. A study of meaning and architecture. In: NASAR, Jack. Environmental: Aesthetics: Theory, research, \& applications. New York: Cambridge University Press, 2008, p. 86 100.

MADARIAGA, Inês. Urbanismo con perspectiva de género. Junta de Andaluzia: Instituto Andaluz de la Mujer, 2006.

MARICATO, Hermínia. Brasil, cidades alternativas para a crise urbana. Petrópolis: Vozes. 2008.

QUIVY, Raymond; CAMPENHOUDT, Luc. Manual de Investigação em Ciências Sociais. Lisboa: Gradiva. 2005.

RECKTENWALD, Joachim (Ed.). The life of women and men in Europe: a statistical portrait. Luxemburg: Eurostat, 2008.

Royal Town Planning Institute. New Vision for Planning. 2001. Londres: RTPI em http://www.rtpi.org.uk/download/245/RTPINew-Vision-for-Planning.pdf

Recebido em 21 de setembro de 2012. Aceito em 29 de agosto de 2013. 